\title{
Gestão da Informação por meio físico e digital em Biblioteca Escolar: identificação de interesses dos usuários e tomada de decisão
}

\author{
Information management for physical and digital media in school library: identifying \\ interests of users and decision making
}

Douglas Guioroni Guaitorini Novelletto Pós-graduado em Gestão de Bibliotecas Escolares. E-mail: dgnovell@gmail.com

William Barbosa Vianna

Doutor em Engenharia de Produção pela Universidade Federal de Santa Catarina - UFSC. Professor do Departamento de Ciência da Informação da Universidade Federal de Santa Catarina - UFSC.

E-mail: wpwilliam@hotmail.com

\begin{abstract}
Moisés Lima Dutra
Doutor em Ciências da Computação pela Université Claude Bernarde Lyon 1, França. Professor do Departamento de Ciência da Informação da Universidade Federal de Santa Catarina - UFSC.

E-mail: moises.dutra@ufsc.br
\end{abstract}

\section{Resumo}

O objetivo do estudo foi identificar aspectos do comportamento de usuários de uma Biblioteca Universitária e Escolar do Município de Blumenau - SC, para subsidiar a qualificação da oferta de acervo digital de caráter educacional, bem como o desenvolvimento de políticas de atendimento ao usuário e desenvolvimento de coleções. Justifica-se pela utilidade de conhecer o comportamento do usuário para subsidiar o desenvolvimento de políticas de acervo digital, desenvolvimento de coleções e orçamento para investir na aquisição de Bases de Dados e Livros Digitais (ebooks). A metodologia utilizada é exploratória e quantitativa com aplicação de questionário. Os resultados apontaram para relevância e preferência pelo acesso a conteúdos digitais de forma prática e contínua, também contribuem para tomada de decisão quanto ao desenvolvimento de coleções.

Palavras-chave: Gestão da Informação. Biblioteca Escolar. Tomada de Decisão.

\begin{abstract}
The objective of the study was to identify user behavior aspects of a University Library and School of the Municipality of Blumenau - SC, to support the qualification of the supply of digital library of educational character as well as the development of the user service policies and development of collections. Justified by the usefulness of knowing the user's behavior to support the development of digital collection policies, collection development budget to invest in the acquisition of databases and digital books (ebooks). The methodology used is exploratory and quantitative with questionnaire. The results pointed to importance and preference for access to digital content and practice continuously and contribute to decision making for the development of collections.
\end{abstract}

Keywords: Information Management. School Library. Decision taking

Bibl. Esc. em R., Ribeirão Preto, v. 4, n. 2, p. 53-74, 2016. 


\section{Introdução}

No atual contexto de desenvolvimento da sociedade da informação, a constituição da Biblioteca Escolar Digital será fundamental para a construção dessa rede de conhecimento digital para produção de conhecimento organizado e disseminado a toda uma comunidade (SANTOS; AMARAL, 2006).

O contato com o meio literário possibilita a ampliação significativa da leitura do mundo, o que é de fundamental importância na construção de um protagonismo social dos estudantes.

Um dos importantes papéis educacionais da biblioteca escolar é incentivar a leitura reflexiva, pois por meio dela o aluno terá outra concepção do texto, não como algo estático, desprovido de sentido e de valor, mas como algo vivo, repleto de significados e informações interessantes (SANTANA FILHO, 2005).

Nesse sentido, a biblioteca escolar passa a ser um espaço que necessita de um olhar particular, pois a ela cabe oferecer entre outros atrativos um acervo atualizado e possiblidades físicas e digitais de qualidade para que os leitores a procurem, caso contrário, irão afastar-se dela.

No caso, é fundamental levar em consideração a mudança rápida nas formas de acessar a informação por parte dos chamados "nativos digitais".

Os alunos de hoje - do maternal à faculdade - representam as primeiras gerações que cresceram em contato direto com novas tecnologias. Eles passaram a vida inteira cercados e usando computadores, vídeo games, tocadores de música digitais, câmeras de vídeo, telefones celulares, e todos os outros brinquedos e ferramentas da era digital (PRENSKY, 2004).

Buckingham (2008) alerta para necessidade de cautela com a retórica da "geração digital", ou seja, a ideia de que os alunos estão ativamente se comunicando e criando on-line conteúdo educativo.

O autor nomeia de cultura popular o que os jovens estão fazendo no computador em casa, jogando, surfando nos sites de entretenimento, trocando mensagens instantâneas, participando de redes sociais, baixando e editando vídeos e músicas, e alerta que muito pouco é feito de tarefa escolar. 
Frente às facilidades e diversidades em encontrar conteúdo na internet, que é a rede mundial de computadores, nos deparamos com o problema de estabelecer critérios na escolha do acesso à informação através do meio físico ou do meio digital no ambiente das bibliotecas escolares.

É bastante comum encontrar em bibliotecas escolares estudantes fazendo trabalhos de pesquisa utilizando somente computadores por conta própria, ou seja, numa busca livre e não apoiada ou assessorada de forma educativa por profissionais qualificados, sejam eles professores ou bibliotecários.

Nesse caso, o aprendizado pode estar ocorrendo por meio de um conteúdo digital não qualificado educativamente, ou seja, há bastante conteúdo criado de forma livre e cheio de equívoco, desfavorecendo a leitura educativa e de fontes qualificadas dentro do contexto escolar, capazes de desenvolver a sensibilidade, a percepção, a imaginação e o raciocínio; atividades que não são totalmente atingidas na leitura individualizada de material digital.

Considerando que a escolha entre os conteúdos físicos e digitais pode ocorrer de forma subjetiva e ser ineficaz do ponto de vista educativo, é útil identificar quais são os fatores que motivam a opção por um ou outro meio.

Nesse sentido, pergunta-se: quais aspectos são relevantes para tomada de decisão quanto à destinação de recursos aos acervos físicos e digitais?

O objetivo do estudo foi identificar aspectos do comportamento de usuários de uma Biblioteca Universitária e Escolar para subsidiar a qualificação da oferta de acervo digital de caráter educacional, bem como o desenvolvimento de políticas de atendimento ao usuário e desenvolvimento de coleções.

Justifica-se pela necessidade de melhoria constante da Biblioteca no atendimento dos usuários que tem modificado os padrões de comportamento na busca informacional, substituindo por vezes o acervo físico qualificado por conteúdos digitais desqualificados, podendo gerar equívocos de aprendizagem.

Do ponto de vista de seus objetivos esse estudo é exploratório, pois inicialmente por meio do levantamento bibliográfico, foi possível obter uma maior familiaridade com o problema. Em seguida, as diversas entrevistas em forma de conversa com os gestores da biblioteca e que não constam explicitados neste trabalho também contribuirão para um aumento 
Gestão da Informação por meio físico e digital em Biblioteca Escolar: identificação de interesses dos usuários e tomada de decisão

de conhecimento sobre o assunto. E por fim, os resultados representarão um avanço no conhecimento sobre o tema.

Para Gil (2002, p. 41):

A pesquisa exploratória visa proporcionar maior familiaridade com o problema com vistas a torná-lo explícito ou a construir hipóteses. Envolve levantamento bibliográfico; entrevistas com pessoas que tiveram experiências práticas com o problema pesquisado; análise de exemplos que estimulem a compreensão. Assume em geral as formas de pesquisas bibliográficas e estudos de caso.

Do ponto de vista da abordagem direta do problema esse estudo é quantitativo, pois a análise foi baseada nas medidas numéricas abstraídas dos questionários.

Conforme Marconi e Lakatos (2010, p. 75):

A pesquisa quantitativa considera que tudo pode ser quantificável, o que significa traduzir em números opiniões e informações para classificá-las e analisá-las. Requer o uso de recursos e técnicas estatísticas (percentagem, média, moda, mediana, desvio-padrão, coeficiente de correlação, análise de regressão e outros).

O levantamento de dados foi feito por meio de questionários onde foram coletadas respostas sobre questões baseadas no interesse dos gestores da biblioteca cujos resultados estão representados por meio dos gráficos que permitiram a análise dos dados.

O conteúdo dos questionários foi construído a partir de entrevistas não-estruturadas com gestores da Biblioteca para, em seguida serem elaboradas 16 questões que ficaram disponíveis no balcão de auto-empréstimo, sendo este um local de grande circulação por parte dos usuários da Biblioteca, durante o horário das 7:30 horas até às 22:00 horas dentre os dias 8 e 12 de junho de 2015.

Com mais de 500 mil volumes, 5,4 mil $\mathrm{m}^{2}$ de espaço físico e 1 milhão de empréstimos anuais em média, a Biblioteca Universitária Prof. Martinho Cardoso da Veiga, da Universidade Regional de Blumenau - Santa Catarina - Brasil, é Instituição de Ensino Superior criada e mantida pela Fundação Universidade Regional de Blumenau - FURB. Situada no campus 1 em Blumenau possui um dos maiores acervos do estado.

A Biblioteca Universitária mantém unidades setoriais no campus 2 e campus 3, facilitando consultas ou empréstimos. É oferecido ao usuário o serviço de Empréstimo entre Bibliotecas, possibilitando que o livro chegue até o leitor sem que ele se desloque entre os campus da FURB. 
A Biblioteca abrange ainda o atendimento a mais de 400 alunos da Escola Técnica do Vale do Itajaí (ETEVI) nível médio, caracterizando-se também como Biblioteca Escolar, da mesma forma que diversas outras Bibliotecas do sistema da Associação Catarinense das Fundações Educacionais (ACAFE).

Em 1974, os presidentes das fundações criadas por lei municipal e estadual constituíram a ACAFE, entidade sem fins lucrativos, com a missão de promover a integração dos esforços de consolidação das instituições de ensino superior que incorporaram também atividades de Educação Básica.

Os resultados apontaram para identificação de aspectos de comportamento do usuário capazes de subsidiar os bibliotecários na decisão sobre as ferramentas de auxílio às suas atividades de atendimento ao usuário no sentido de fornecer alternativas de escolha de conteúdo em meio físico ou digital como exemplo as Bases de Dados ou Google Acadêmico, bem como como políticas de acervo digital, desenvolvimento de coleções e valores percentuais do orçamento para investir na aquisição de Bases de Dados e Livros Digitais (ebooks).

\section{Desafios das TIC para as Bibliotecas Escolares}

Vivemos na sociedade do conhecimento, onde as informações, que são muitas, surgem a cada instante e se modificam rapidamente, entretanto, não basta possuir ou ter acesso a informação, é preciso desenvolver competências informacionais para sua adequada utilização. Por vezes o professor pode se questionar sobre o que fazer com tanta informação em relação ao uso das mesmas no ensino das disciplinas escolares, o mesmo acontecendo com os seus alunos.

Segundo Monereo e Pozo (2010) para mudar as formas de aprender dos alunos, os professores necessitam mudar suas metodologias em sala e que a nova cultura que está presente em nossa sociedade requer um novo perfil de aluno e de professor.

Dentre os papéis da Biblioteca Escolar está o de contribuir para o desenvolvimento da competência informacional, ou seja, como afirma Campello (2002), a biblioteca escolar tem potencial para ser catalisadora das mudanças em face das exigências da educação no século XXI.

Carlson (2002) afirma que a missão da biblioteca antigamente era a de adquirir, organizar e tornar a informação acessível. Tal concepção tem sido reformulada e aponta para 
Gestão da Informação por meio físico e digital em Biblioteca Escolar: identificação de interesses dos usuários e tomada de decisão

biblioteca como uma entidade que conecta utilizadores a conhecimento e os computadores nunca serão demasiados, os livros é que serão sempre poucos.

Pereira (2004) considera que o contexto informacional de mudança revela uma nova missão para a biblioteca - a de contribuinte de conteúdos digitais disseminados pela Internet, deixando de ser detentora do "corpo físico" que contém a informação, assumindo, essencialmente, um papel de intermediária.

Nesse sentido, consideramos nesse estudo que um dos papéis da Biblioteca Escolar é auxiliar os estudantes a selecionar de forma adequada as informações que chegam até eles por meio das Tecnologias da Informação e Comunicação (TIC) e orientá-los para que aproveitem ao máximo as que realmente são relevantes para o seu aprendizado escolar.

Tal se deve ao fato de que a escola não é mais apenas uma detentora do conhecimento, mas articuladora, ou seja, à escola cabe trabalhar alternativas que possibilitem relacionar essas informações com o cotidiano, onde elas se aplicam, qual a importância de cada uma na vida das pessoas e discutir sobre quais informações possuem relevância, e se foram extraídas de uma fonte confiável.

Considera-se também que entre as funções da escola do século XXI está a de repensar suas práticas pedagógicas e a maneira como está organizada, bem como rever seu papel na sociedade que requer novas competências de gestão do conhecimento, conforme salienta Pozo (2008, p. 32):

Uma das metas essenciais da educação, para poder atender às exigências dessa nova
sociedade da aprendizagem, seria, portanto, fomentar nos alunos capacidades de
gestão do conhecimento ou, se preferirmos, de gestão metacognitiva, já que, para além
da aquisição de conhecimentos pontuais concretos, esse é o único meio de ajudá-los
a enfrentar as tarefas e os desafios que os aguardam na sociedade do conhecimento.

Para Monereo e Pozo (2010) a nova cultura da aprendizagem requer, no mínimo, ensinar aos alunos, a partir das diferentes áreas do currículo, cinco tipos de capacidades para a gestão metacognitiva do conhecimento, que são: a) saberes para a aquisição de informação; b) saberes para a interpretação da informação; c) saberes para a análise da informação; d) saberes para a compreensão da informação e; e) saberes para a comunicação da informação.

Os jovens do século XXI, conhecidos como nativos digitais, estão conectados ao mundo por meio da internet, de smartphones, de tablets entre outros aparelhos eletrônicos. 
Douglas Guioroni Guaitorini Novelletto, William Barbosa Vianna e Moisés Lima Dutra

Cabe esclarecer que nativo digital (digital native) é uma metáfora introduzida por Prensky (COLL; MONEREO, 2010) para caracterizar a pessoa que desenvolve uma vida online (e-life) e para a qual o ciberespaço é parte constituinte do cotidiano.

Sobre os nativos digitais, Prensky (2001) destaca que estão se acostumando a fazer tudo ao mesmo tempo, pois convivem desde cedo com as diferentes linguagens, as quais alteram a maneira como reagem ao arsenal de possibilidades oferecido pela facilidade de acesso à informação no mundo digital.

Já os professores, por motivos culturais, de formação ou outros, podem ainda não ter descoberto o potencial que esse aparato tecnológico possui para educação e para o próprio papel da Biblioteca Escolar nesse novo contexto.

Jenkins (2010) afirma que o primeiro passo para a introdução das tecnologias digitais nas escolas deve ser dado com a prática dos educadores, conhecendo e usando as ferramentas, plataformas e processos, pois a prática torna-se importante para percepção de significados e interesses.

Nesse sentido é interessante o conceito de Coll e Monereo (2010) para imigração digital, ou seja, definem imigrantes digitais como sendo aqueles provenientes de uma cultura anterior, organizada basicamente em torno de textos impressos (e de codificação analógica), e que precisam se adaptar às novas modalidades de interação e comunicação digital.

No caso, tanto a escola quanto a biblioteca possuem como desafio perfazer esse processo de imigração digital. As Tecnologias da Informação e Comunicação (TIC), como o telefone, o correio, o rádio e a televisão apenas iniciaram o desencadeamento de diversos aparelhos que a cada dia se renovam no acesso à informação.

Considera-se que incorporar as TIC seja esse um desafio tanto para Biblioteca Escolar quanto para Educação e mais do que isso, da associação entre Biblioteca e Escola - adaptar-se a novas modalidades de interação e comunicação, promover uma - imigração digital.

Os avanços mencionados tiveram seus impactos nas escolas, pois as pessoas passaram a ter acesso a várias informações e cabia a essa instituição do saber ajudar os indivíduos, ou seja, os estudantes a compreender todos os fatos.

A introdução desses equipamentos nas escolas para serem utilizados pelos professores, como, por exemplo, a televisão, o rádio e o videocassete, substituído, mais tarde, pelo DVD no 
Gestão da Informação por meio físico e digital em Biblioteca Escolar: identificação de interesses dos usuários e tomada de decisão

passado, foi visto como um grande avanço na educação, da mesma forma que hoje as novas TIC que surgiram podem auxiliar o processo educacional e uma melhoria na competência informacional dos estudantes.

Para Moran (1994, p. 44), a televisão e o vídeo seriam mecanismos interessantes para dar mais vida à educação, pois operam imediatamente com o sensível, o concreto, principalmente a imagem em movimento. Combinam a dimensão espacial com a cinestésica onde imagem, palavra e música se integram dentro de um contexto comunicacional afetivo, de forte impacto emocional, que facilita e predispõe a conhecer mais favoravelmente.

No que se refere ao computador, Valente (2008, p. 21) afirma que:

[...] deve ser utilizado como um catalisador de uma mudança no paradigma educacional. Um novo paradigma que promove a aprendizagem, ao invés do ensino, que coloca o controle do processo de aprendizagem nas mãos do aprendiz e que auxilia o professor a entender que a educação não é somente a transferência de conhecimento, mas um processo de construção do conhecimento pelo aluno, como produto do seu próprio engajamento intelectual ou do aluno como um todo. Portanto, o objetivo da introdução do computador na educação não deve ser o modismo ou estar atualizado com relação às inovações tecnológicas.

É importante ressaltar que trabalhar com as TIC em sala de aula não significa, necessariamente, abandonar tudo o que já era feito antes - as aulas com quadro e giz, a leitura de livros, os exercícios, por exemplo - mas incorporar as tecnologias na prática pedagógica, para diversificação das aulas, para auxiliar os estudantes a desenvolver destrezas e habilidades relacionadas ao domínio das tecnologias e para apoiar algum aspecto ou conteúdo da aprendizagem (COLL; MONEREO, 2010). 


\section{Formas de acesso físico e digital, leitura e possibilidades para Biblioteca Escolar}

Para Silva (1993, p. 56), a leitura de textos se coloca como uma ajuda para o mundo, sendo importante que essa janela fique sempre aberta, possibilitando desafios cada vez maiores.

A leitura está presente em todas as disciplinas curriculares e em todos os momentos, sendo importante que possa cumprir a sua função social de forma competente, que sua passagem resulte na apropriação de conhecimentos e habilidades significantes para o indivíduo inserido na sociedade.

É preciso, portanto, oferecer-lhes os textos do mundo: não se formam bons leitores solicitando aos alunos que leiam apenas durante as atividades na sala de aula, apenas no livro didático, apenas porque o professor pede. Eis a primeira e talvez a mais importante estratégia didática para a prática de leitura: o trabalho com a diversidade textual. Sem ela, pode-se até se ensinar a ler, mas certamente não se formarão leitores competentes (BRASIL, 1997, p. 55)

A edição de 2014 da pesquisa Retratos da Leitura no Brasil, encomendada pela Fundação Pró-Livro e pelo Ibope Inteligência, que estuda o comportamento do leitor brasileiro mostrou que apesar de a maioria dos brasileiros afirmarem que existem bibliotecas em seu bairro ou cidade, $75 \%$ deles disseram que não frequentaram uma biblioteca em 2013.

Por sua vez, interagir no mundo dos aplicativos e dos tablets, escritores e leitores podem criar novas formas de relação com a leitura, onde "ler e escrever" ganham novos significados. E tais possibilidades podem ser melhor exploradas pelas Bibliotecas Escolares.

Para Santos e Amaral (2006, p. 65), é possível ensinar, de forma didática e pedagógica, os alunos a publicar e construir o acervo digital escolar por meio de seus trabalhos de sala de sala, permitindo a transição do acervo da biblioteca tradicional para o acervo digital, mediado pelo computador.

A utilização das TIC na escola e, particularmente nas atividades que envolvem aula, leitura e biblioteca tem um alto potencial de melhoria dos processos de aprendizagem e ao desenvolvimento das competências informacionais.

A TIC como instrumentos psicológicos mediadores dos processos intra e intermentais pode se desenvolver, basicamente, em duas direções de mediação: a) as relações entre os participantes - especialmente os estudantes, mas também os professores - e os conteúdos de 
aprendizagem e; b) as interações e as trocas comunicacionais entre os participantes, seja entre professores e estudantes, seja entre os próprios estudantes (COLL; MONEREO, 2010).

Para que o processo de leitura e interação digital aconteça basta existir um leitor e um dispositivo computacional com acesso a internet ou não, pois os conteúdos podem estar armazenados nos mais diversos dispositivos de armazenamento como CD, DVD, Pen Drive, Disco Rígido, dentre outros.

Nesse sentido, é possível desenvolver estratégias para interagir com a diversidade de textos escritos, testemunhar a utilização que os já leitores fazem deles, e participar de atos de leitura de fato com a possibilidade de negociar o conhecimento que já se tem e o que é apresentado pelo texto, o que está atrás e diante dos olhos, recebendo incentivo e ajuda de leitores experientes tanto na sala de aula como no espaço da biblioteca.

Pode-se ainda integrar nesse processo os novos formatos para a produção textual, que são escritas e lidas simultaneamente online, se integram ao audiovisual e podem ser lidas por comunidades, que também participam dos seus desdobramentos enviando conteúdos e feedback.

Se antes apenas baixávamos um livro em formato $e$-book ou pdf, agora temos os apps (um software aplicativo específico) para termos o mesmo material nos tablets, com a possibilidade de acessar e criar textos falados, escritos, imagens, sons, interações em diversas camadas.

Na nova sociedade da informação, da aprendizagem e do conhecimento, o papel mais importante do professor em ambientes virtuais, entre os que identificamos, é o de mediador, entendido como alguém que proporciona auxílios educacionais ajustados à atividade construtiva do aluno, utilizando as TIC para fazer isso. (COLL; MONEREO, 2010, p. 129-133).

É nesse sentido de incorporar novas tecnologias e formas de produção e interação na produção textual, acesso e uso de conteúdo digital associado ao conteúdo físico e aos processos de ensino e aprendizagem que a Biblioteca pode se valer para se desenvolver nesse novo contexto. 


\section{Apresentação de resultados e análise}

O presente estudo foi aplicado nas dependências da Biblioteca Central da Universidade Regional de Blumenau que possui aproximadamente 10.000 alunos matriculados em seus diversos níveis de ensino e que compõem a população total deste trabalho.

Para a composição da amostra de 50 cinquenta questionários foram utilizados o critério de preenchimento aleatório por parte dos frequentadores da Biblioteca que cursam o Ensino Médio.

Neste tipo de seleção, a amostra pode ser feita quando o objetivo não é generalizar os resultados, mas sim, obter boas ideias e opiniões críticas experientes, sendo recomendada para pesquisas nas quais o objetivo é o entendimento em profundidade dos casos estudados. (SELLTIZ, 1987, p. 19).

Após o término do prazo para preenchimento dos 50 questionários pelos usuários da Biblioteca os questionários foram novamente agrupados e tiveram tabuladas e totalizadas as 16 questões de múltipla escolha e uma discursiva através da utilização de Planilha de Cálculos MS-Excel 2010. Os usuários que responderam ao questionário não foram identificados e os resultados são apresentados a seguir.

Na questão de número 1, pretendeu-se identificar o sexo dos alunos que participaram da pesquisa. No gráfico 1 são apresentados os resultados.

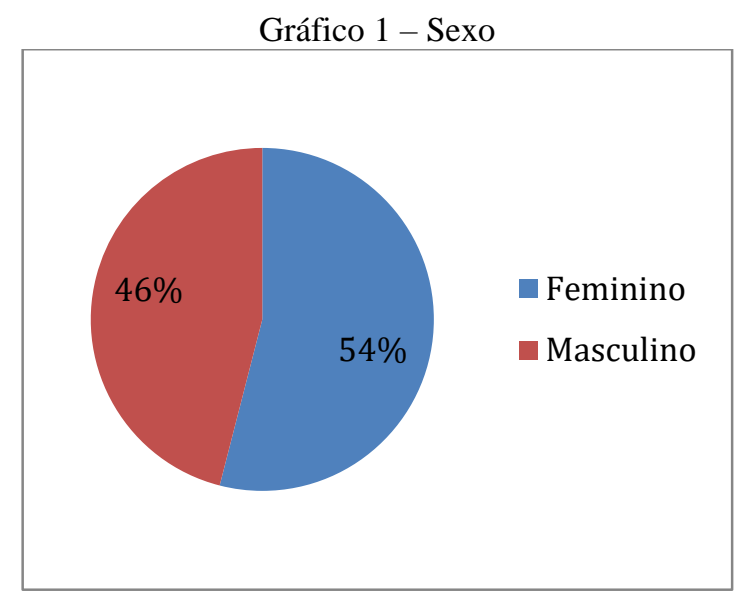

Fonte: dados da pesquisa (2015).

A maioria dos formulários foi respondida pelo sexo feminino (27), sendo que também a maioria dos alunos da instituição é constituído por mulheres. 
Gestão da Informação por meio físico e digital em Biblioteca Escolar: identificação de interesses dos usuários e tomada de decisão

A questão 2 foi incluída para medir qual público frequenta a Biblioteca, uma vez que a mesma é aberta para alunos do SENAI, SENAC, UFSC (polo Blumenau e Florianópolis), Ibis, Uniasselvi, Fundação Fritz Mueller, Fundação Getúlio Vargas, todas essas instituições com polos presenciais na cidade de Blumenau e muitos alunos de outras instituições locais.

Gráfico 2 - É aluno da Instituição?

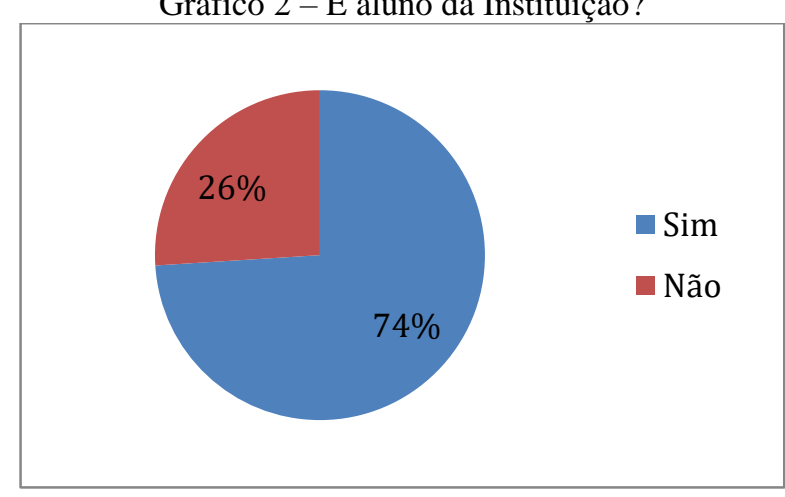

Fonte: dados da pesquisa (2015)

Durante o período de coleta de respostas para os questionários deste estudo foi verificado que cerca de $30 \%$ dos frequentadores é visitante. Essa informação permite inferir que a Biblioteca atende uma parcela significativa de Ensino Médio da região, sendo possível propor atividades integradoras e interativas que envolvam busca e recuperação da informação a partir da identificação das necessidades informacionais dos usuários ao frequentarem a Biblioteca.

A questão 3 se refere ao nível educacional dos respondentes, tendo em vista que a Biblioteca embora se encontre numa instituição de ensino superior, também é aberta a alunos de Educação Básica.

Gráfico 3 - Está cursando:

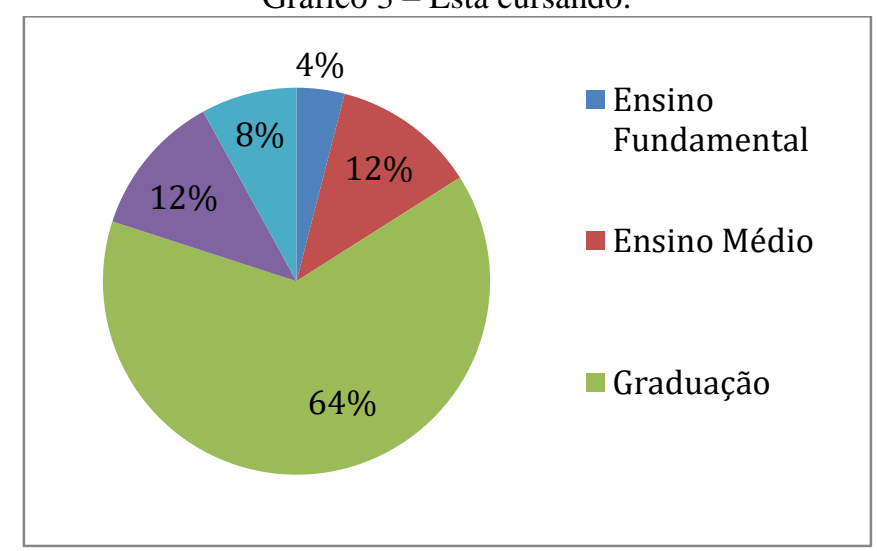

Fonte: dados da pesquisa (2015) 
Os respondentes de Educação Básica representaram 20\% da amostra sendo que $8 \%$ eram do Ensino Fundamental e 12\% do Ensino Médio. Esse percentual confirma o papel da Biblioteca como prestadora de serviços a alunos de Educação Básica e interações com os cursos superiores voltados para a formação de professores ou associados à educação poderiam contribuir com projetos de leitura, uso e recuperação da informação, interações entre os participantes na apropriação dos conteúdos de aprendizagem buscados na biblioteca, trocas comunicacionais entre os participantes, seja entre professores e estudantes, seja entre os próprios estudantes com a mediação do bibliotecário, dentre outras possibilidades.

A questão 4 aborda sobre o gosto pela leitura.

Gráfico 4 - Gosta de ler?

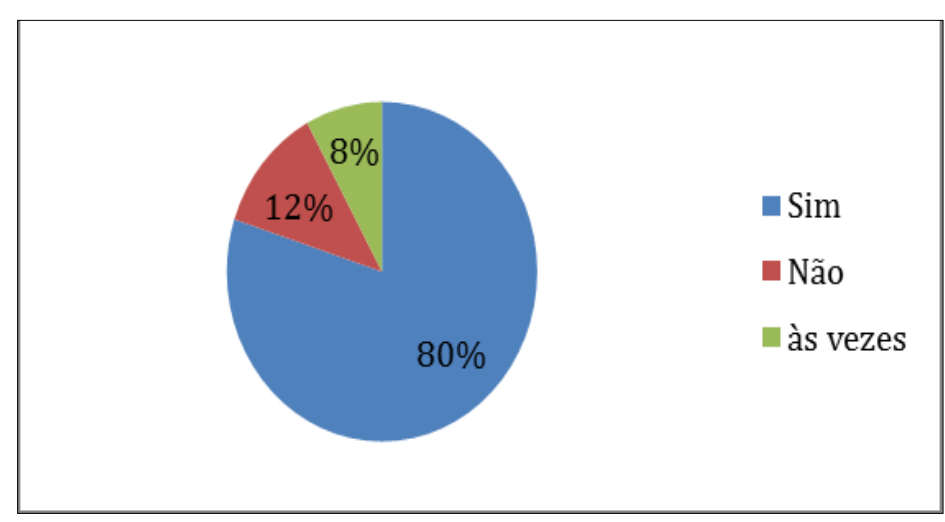

Fonte: dados da pesquisa (2015)

Neste gráfico notou-se que a grande maioria dos usuários $(80 \%)$ que responderam ao questionário gostam de ler, o que abre diversas possibilidades de uso da leitura como mediadora de atividades educativas que envolvam diversos aparatos de tecnologia da informação e da comunicação como motivadores do ato de ler e desse como possibilidades de aprendizado e trocas sociais.

Na questão 5 a interrogação se referiu à frequência à biblioteca em termos de regularidade. 
Gráfico 5 - Frequenta a Biblioteca com que regularidade?

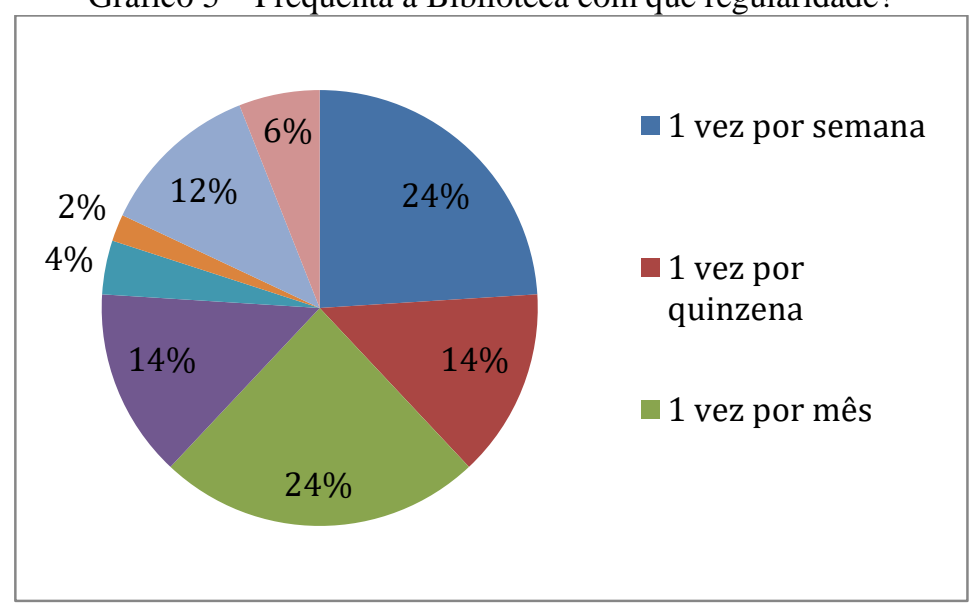

Fonte: dados da pesquisa (2015).

As respostas apontam uma frequência regular de, ao menos uma vez por mês por parte de $24 \%$ dos respondentes e $38 \%$ somados uma vez por semana e uma vez a cada quinze dias. Por meio de observação foi possível identificar que durante a coleta houveram 4 visitas orientadas com acompanhamento do professor.

Tanto a regularidade de frequência quanto as visitas orientadas oferecem possibilidades de projetos e programas de qualificação da escolha entre os conteúdos físicos e digitais, com apoio profissional, seja do bibliotecário, de professores ou de ambos no sentido de apoiar a tarefa educativa de recuperação relevante da informação.

Com o intuito de verificar a utilidade do acervo disponível ao visitante da Biblioteca o pesquisador verificou na questão 6 se na biblioteca são encontrados livros ou periódicos de interesse do entrevistado. 


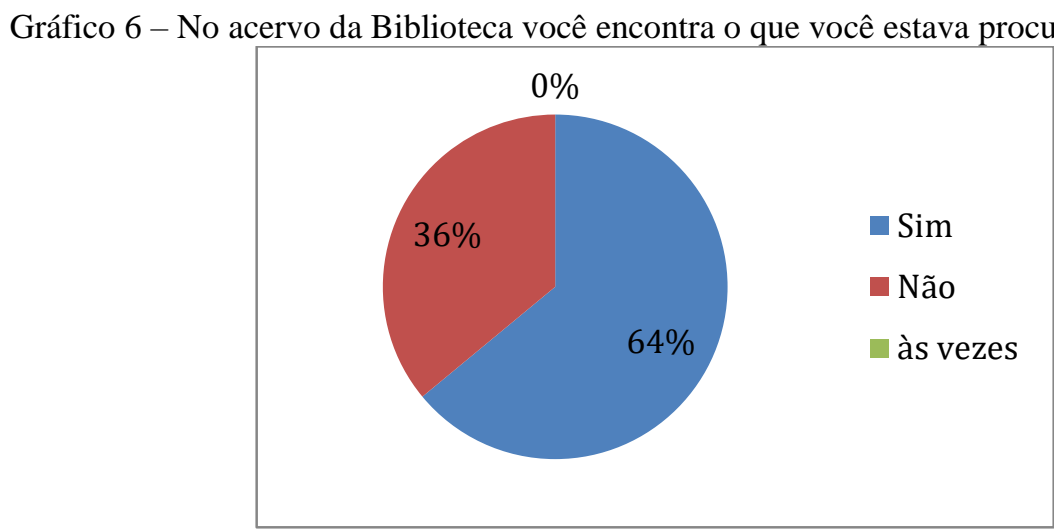

Fonte: dados da pesquisa (2015)

Apesar de possuir um acervo considerável, uma boa parte dos respondentes (36\%) informaram que nem sempre o usuário tem sua demanda atendida. Restaria identificar se realmente o conteúdo não existe no acervo ou não foi localizado por estar emprestado, em uso ou pelo fato do usuário não saber procurar no sistema de busca. Faz-se necessário um estudo maior envolvendo os bibliotecários para que seja apurado se existe parte do que estava sendo procurado no acervo ou não existe em sua integralidade, talvez um futuro estudo possa revelar esta informação.

A questão 7 aborda a forma com que os respondentes tiveram seus primeiros contatos com a leitura.

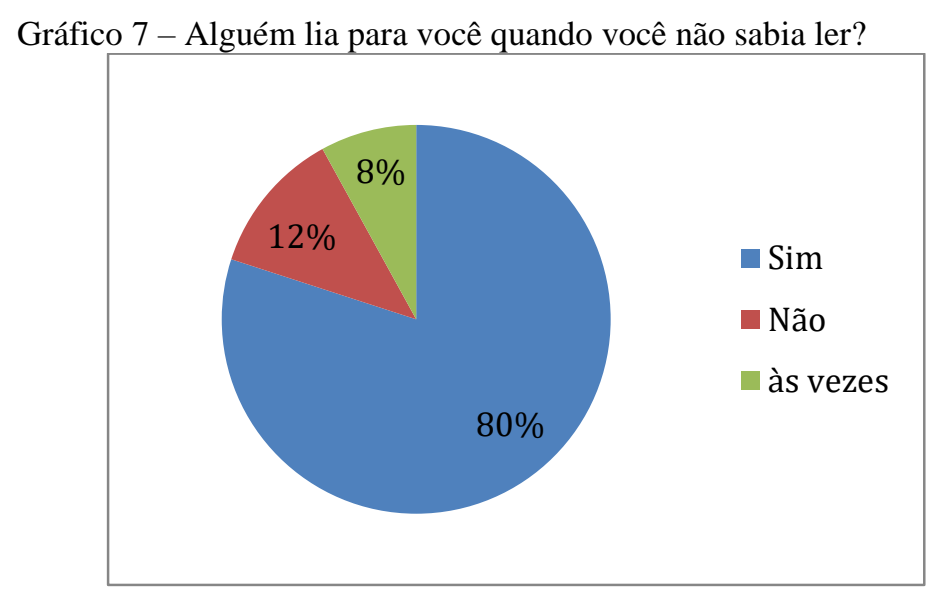

Fonte: dados da pesquisa (2015).

Nesta questão ficou nítido que o público que chegou até o Ensino Médio e Graduação felizmente em sua maioria por meio de alguma atividade mediada de leitura. Nesse sentido, os processos de mediação e interação no processo de ler já é familiar aos respondentes.

Na questão 8 foi perguntado acerca da forma de acesso ao livro. 
Gestão da Informação por meio físico e digital em Biblioteca Escolar: identificação de interesses dos usuários e tomada de decisão

Gráfico 8 - Como você consegue livros para ler?

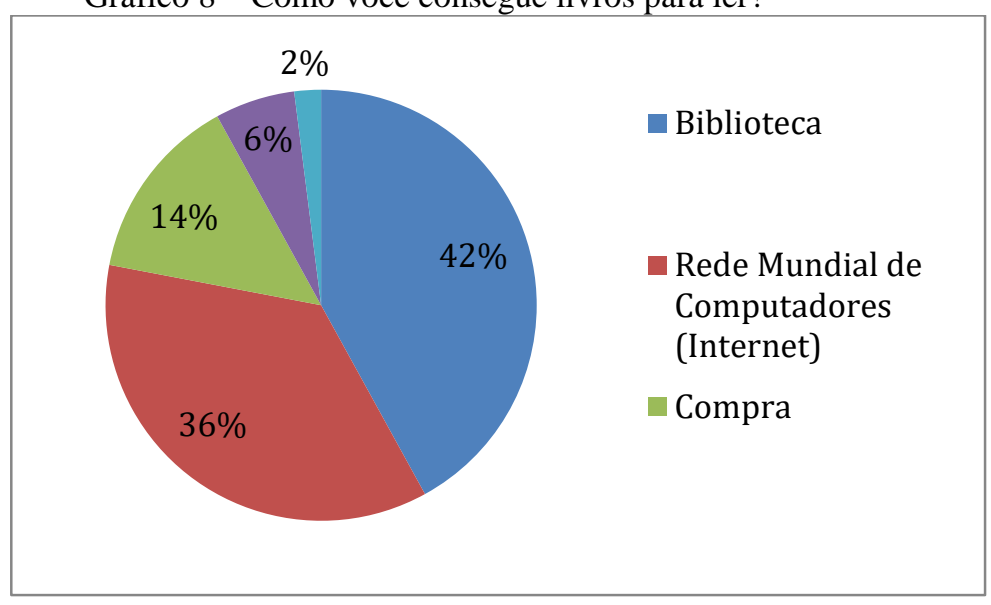

Fonte: dados da pesquisa (2015)

Apesar de o gráfico demonstrar que a maioria dos livros lidos é no formato físico e obtidos na Biblioteca, o número de livros baixados em formato PDF por meio de diversos sites que disponibilizam para Download ou base de dados é significativo (36\%), aproximando-se muito da busca em Biblioteca, com uma pequena diferença de 5\%. Tal fato aponta para necessidade da Biblioteca investigar de forma mais aprofundada formas de incorporar serviços de atendimento especializado que apoiem e qualifiquem essa busca na internet.

A questão 9 abordou o tipo de leitura preferida pelos respondentes.

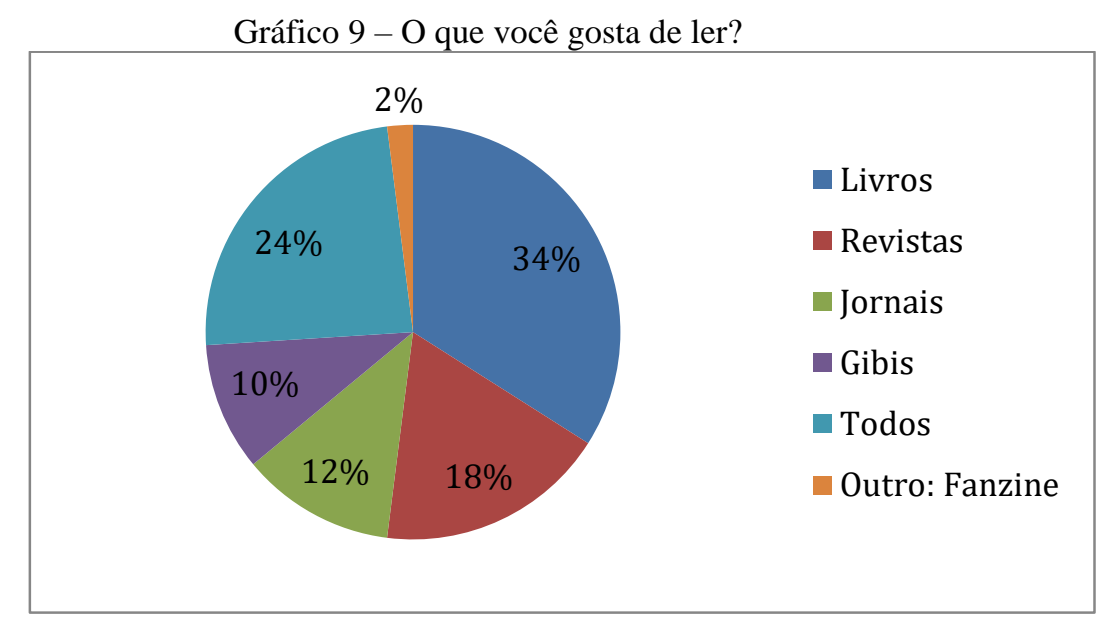

Fonte: dados da pesquisa (2015)

Uma parte significativa dos respondentes (34\%) apontou para preferencia por livros. Entretanto, outros tipos de leitura despertam o interesse dos usuários tal como revista, jornais e gibis o que aponta para interesse diversificados de acesso à informação.

A questão 10 questionou acerca do livro didático. 


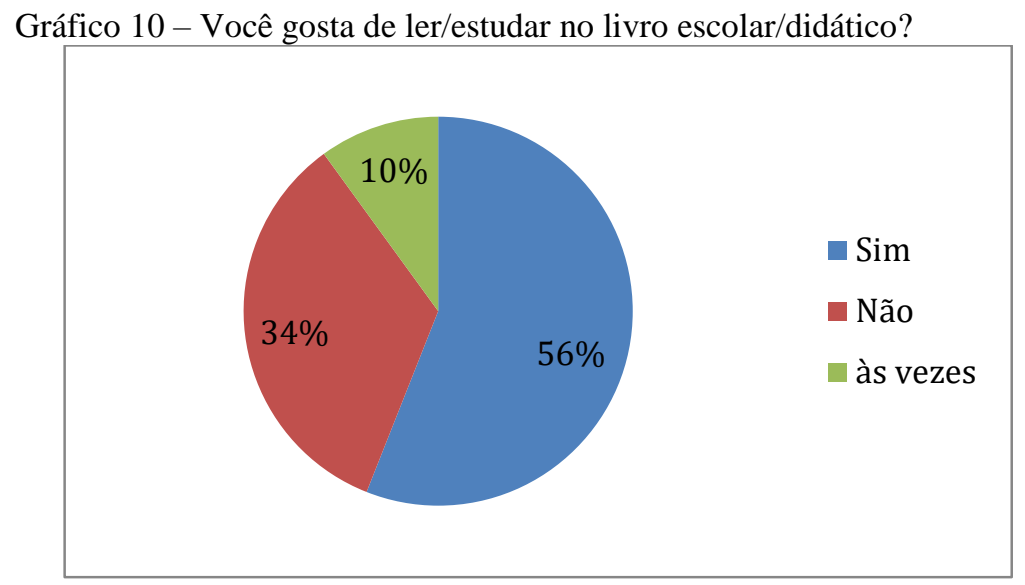

Fonte: dados da pesquisa (2015).

O gosto pelo livro didático tal como se apresenta em formato físico, apesar de representar o gosto da maioria dos respondentes, não deixa de contrastar com o resultado significativo dos que não gostam ou gostam apenas às vezes.

Novas investigações mais aprofundadas sobre o que esse resultado representa poderia potencializar o desenvolvimento de projetos e programas baseados na associação de recursos e na colaboração entre os professores e a biblioteca no desenvolvimento das coleções com uma maior variedade de possibilidades e suportes, de acordo com o interesse dos usuários que como foi verificado na questão 8 , usam a internet para acessar conteúdo de livros.

A questão 11 se refere à preferência pelo material físico tradicional.

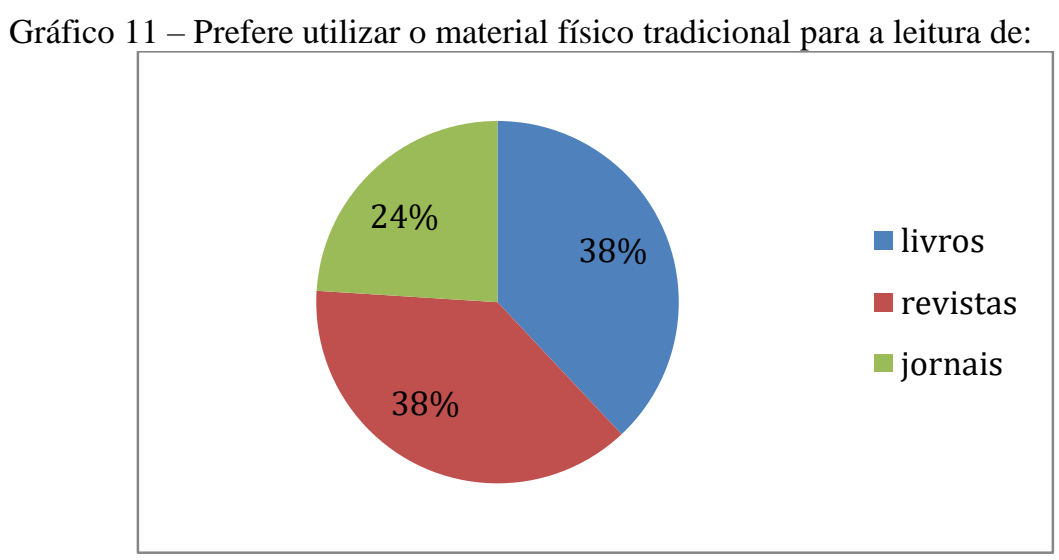

Fonte: dados da pesquisa (2015).

Nesta questão houve praticamente um empate entre as 3 opções listadas, demonstrando que o material físico é utilizado pelos usuários.

A questão 12 se referiu à preferência sobre o uso de material digital. 
Gestão da Informação por meio físico e digital em Biblioteca Escolar: identificação de interesses dos usuários e tomada de decisão

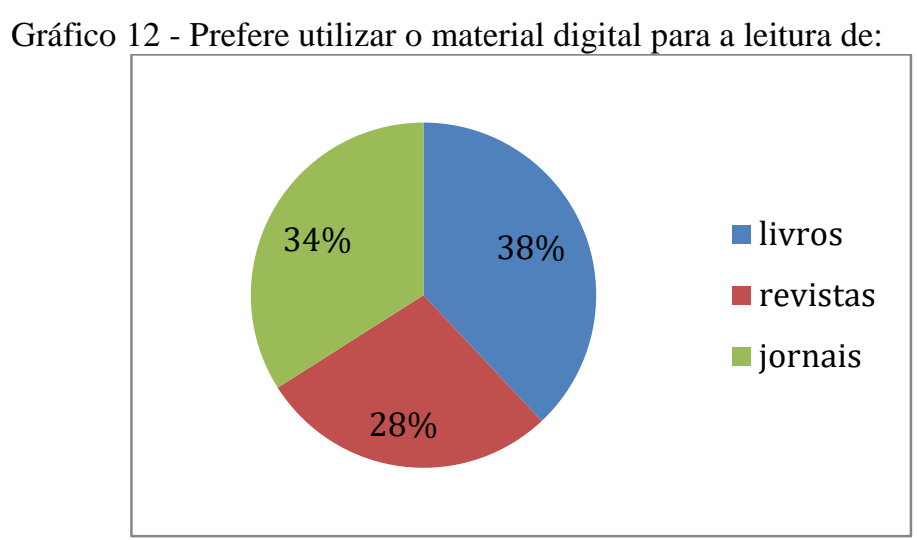

Fonte: dados da pesquisa (2015)

Os usuários demonstraram interesse considerável (38\%) no uso do livro digital, seguido de revistas e jornais. A Biblioteca pode se valer do fato de que as novas gerações identificamse com outras formas de leitura e há diferentes processos de apropriação dos textos e da informação, em que novas modalidades de aprendizagem podem ser desenvolvidas com o uso associado de livros, revistas e jornais.

Na questão 13 perguntou-se sobre o papel do design gráfico na escolha entre o meio físico e digital.

Gráfico 13 - Se um conteúdo estiver disponível em meio físico e digital, o visual interfere na escolha?

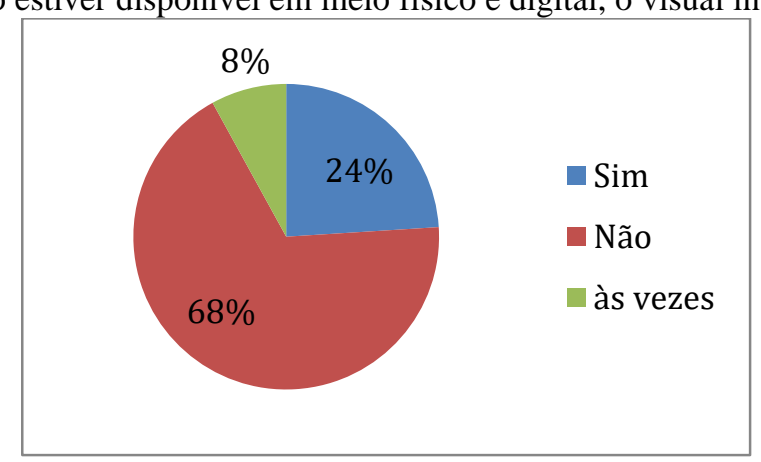

Fonte: dados da pesquisa (2015)

Segundo a maioria dos usuários que responderam aos questionários o visual do material não possui influência determinante no momento da escolha, o que revela, de certa forma que o usuário tem preferência por outros atributos que podem ser conteúdo, facilidade de recuperação ou outro, o que merece maior investigação.

A questão 14 tratou da velocidade de acesso à internet na seleção do meio de busca da informação. 
Douglas Guioroni Guaitorini Novelletto, William Barbosa Vianna e Moisés Lima Dutra

Gráfico 14 - A velocidade de acesso interfere na hora da escolha pelo material em meio físico ou digital?

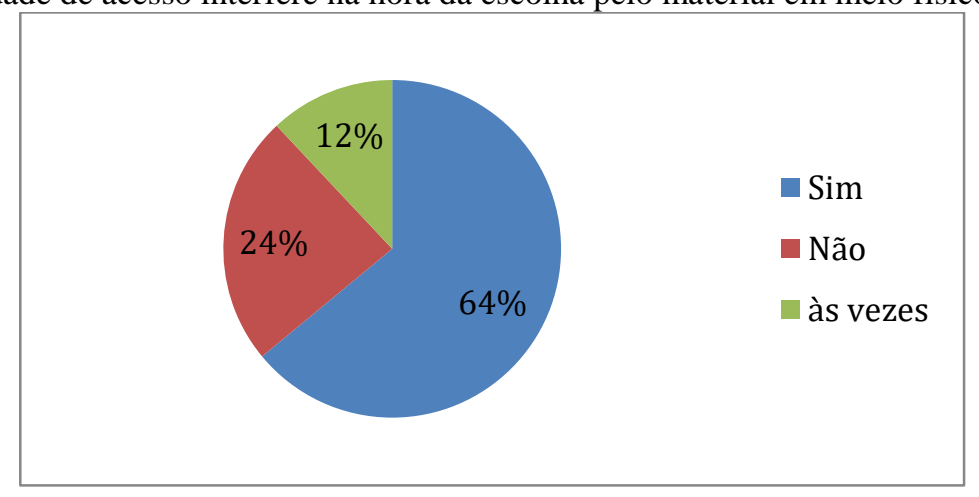

Fonte: dados da pesquisa (2015)

Nesta questão ficou evidente o relevante papel da tecnologia de acesso para recuperação da informação e que as dificuldades de tecnologia tanto infraestrutura de hardware como de software (base de dados, licenças) envolvidas em todo o processo de acesso à Informação com qualidade, merece investimentos e atenção no espaço da biblioteca escolar.

A questão 15 abordou sobre a disponibilidade de conteúdo digital.

Gráfico 15 - Disponibilidade em qualquer lugar interfere na hora da escolha entre físico e digital?

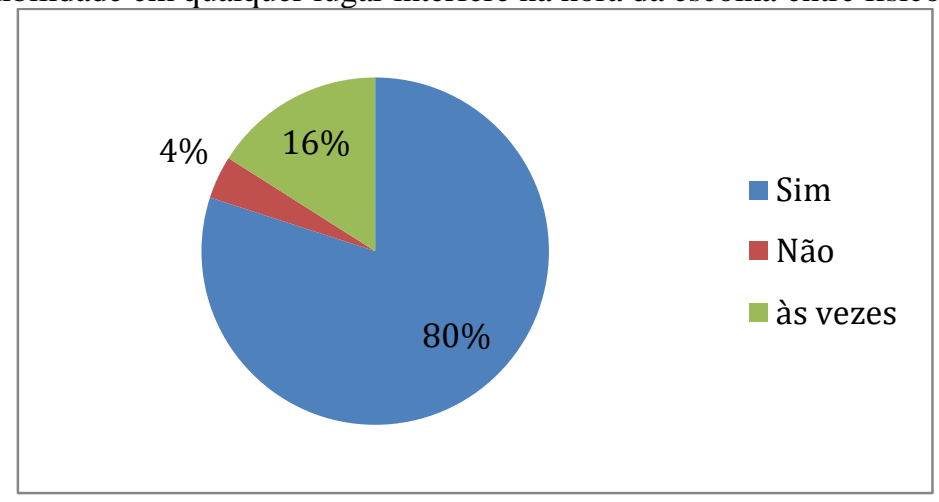

Fonte: dados da pesquisa (2015).

Percebe-se que se disponibilizado com segurança, frequência e rapidez o meio digital em breve será o meio mais acessado para o acesso e tal fato é relevante para o futuro da biblioteca escolar.

Na questão discursiva de número 16 - "Cite possíveis fatores que motivam a efetuar a leitura no meio digital", foram elencados: Velocidade de acesso ao conteúdo específico - 4; Praticidade - 16; Disponibilidade a qualquer instante - 8; Agilidade - 11; Fácil acesso - 17; Indisponibilidade do livro em meio físico - 3; Necessidade de ler apenas trechos do livro e não o livro por completo - 5; Variedade de material - 2; Objetividade - 5; Mobilidade - 31; Informalidade -7 . 
A questão 16 confirma a anterior, ou seja, o fácil acesso e a praticidade são fatores fundamentais para preferência pela busca e recuperação da informação em meio digital.

\section{Considerações finais}

O estudo procurou responder à pergunta sobre quais aspectos são relevantes para tomada de decisão quanto à destinação de recursos aos acervos físicos e digitais.

Os resultados evidenciaram nas respostas das questões 12, 14, 15 e 16 que é o acesso em formato digital que é o mais utilizado, porém é fundamental que recursos financeiros sejam investidos nesse sentido, bem como a melhoria da infraestrutura para que isto se torne realidade.

Verificou-se também que diversas possibilidades podem ser exploradas, tendo em vista o interesse dos respondentes que tanto acessam meios físicos quanto digitais, mas que buscam praticidade na recuperação da informação.

Nesse sentido, destaca-se a possibilidade de acesso em qualquer hora e lugar em qualquer lugar e horário a leitura seja efetuada sem a necessidade de possuir o item do acervo em mãos bastando para isso fazer uma conexão; mobilidade - com o advento das tecnologias móveis (celulares, tablets e smartphones, dentre outros), em contraposição ao acesso apenas físico nos horários de funcionamento da biblioteca.

Os fatores identificados na questão 16, muitos deles citados diversas vezes apontam que o usuário aceita e já está bem familiarizado com a prática da leitura em meio digital, dentre eles destacam-se a velocidade de acesso ao conteúdo específico. Nesse caso o fator mobilidade tem sido determinante em várias situações e com a leitura não é diferente, mas para satisfação do usuário é interessante que o conteúdo digital esteja disponível durante 24 horas por dia e em qualquer lugar.

Essa é uma tarefa que desafia os gestores de Biblioteca Escolar, ou seja, investir na implantação de tecnologia, os dispositivos computacionais estão cada vez mais acessíveis em termos de custo e usabilidade e acessibilidade, ou seja, uma nova biblioteca bem estruturada em termos de desenvolvimento de coleções eletrônicas, com critérios de seleção adequada de recursos tem potencial capaz de atrair e fidelizar os jovens respondentes.

E por fim conclui-se que a leitura no ambiente virtual, se bem conduzida, poderá motivar o leitor e propiciar a construção do conhecimento e a valorização da leitura. É possível 
promover o estudo das variadas formas de leitura para adequar o processo ensino-aprendizagem às peculiaridades do uso das TIC pelas novas gerações, mediado por agentes qualificados, quais sejam o bibliotecário e os professores, tendo em vista garantir o acesso e o uso de conteúdo qualificado.

Dessa forma, considera-se que o objetivo do estudo de identificar aspectos do comportamento de usuários de uma Biblioteca Universitária e Escolar para subsidiar a qualificação da oferta de acervo digital de caráter educacional, bem como o desenvolvimento de políticas de atendimento ao usuário e desenvolvimento de coleções foi atendido, sendo úteis novas e aprofundadas investigações sobre aspectos particulares não evidenciados pelas respostas.

\section{Referências}

BRASIL. PCN: parâmetros curriculares nacionais: língua portuguesa. v. 2. Brasília: MEC/SEF (Secretaria da Educação Fundamental), 1997.

BUCKINGHAM, D. Youth and media institute of education. Revista Pátio, London University, v. 11, n. 44, 2008.

CARLSON, S. Do libraries really need books? Controversial projects at some colleges move the printed word out of sight. The Chronicle of Higher Education, section: Information Technology, p. A31, 2002. Disponível em: <http://chronicle.com/free/v48/i44/44a03101.htm>. Acesso em: 10 mar. 2016.

CAMPELLO, B. A competência informacional na educação para o século XXI. In: BIBLIOTECA escolar: temas para uma prática pedagógica. Belo Horizonte: Autêntica, 2002. p. $9-11$.

COLL, C.; MONEREO, C. Psicologia da educação virtual: aprender e ensinar com as tecnologias da informação e comunicação. Porto Alegre: Artmed, 2010.

GIL, A. C. Como elaborar projetos de pesquisa. São Paulo: Atlas, 2002.

JENKINS, H. DIY Media: a contextual background and some contemporary themes. DIY media: creating, sharing, and learning with new technologies, p. 231-252, 2010. Disponível em: 〈http://everydayliteracies.net/files/DIY_Media_ms.pdf\#page=7>. Acesso em: 24 set. 2015.

MARCONI, M. A.; LAKATOS, E. M. Técnicas de pesquisa: planejamento e execução de pesquisas, amostragens e técnicas de pesquisa, elaboração, análise e interpretação de dados. 7 . ed. São Paulo: Atlas, 2010. 
Gestão da Informação por meio físico e digital em Biblioteca Escolar: identificação de interesses dos usuários e tomada de decisão

MONEREO, C.; POZO, J. I. O aluno em ambientes virtuais: condições, perfil e competências. In: COLL, C.; MONEREO, C. Psicologia da educação virtual: aprender e ensinar com as tecnologias da informação e da comunicação. Porto Alegre: Artmed, 2010.

MORAN, J. M. Interferências dos meios de comunicação no nosso conhecimento. Revista Brasileira de Comunicação - INTERCOM, São Paulo, v. 17, n. 2, p. 38-49, 1994.

PEREIRA, A. S. O advento digital e a nova missão da biblioteca pública. In: CONGRESSO DA ASSOCIAÇÃO PORTUGUESA DE BIBLIOTECÁRIOS, ARQUIVISTAS E DOCUMENTALISTAS, 8., 2004, Estoril. Anais eletrônicos... Lisboa: Associação Portuguesa de Bibliotecários, Arquivistas e Documentalistas - BAD, 2004. Disponível em: $\langle$ http://badinfo.apbad.pt/congresso8/ comm6.pdf〉. Acesso em: 14 mar. 2016.

POZO, J. I. A sociedade da aprendizagem e o desafio de converter informações em conhecimento. In: SALGADO, M. U. C.; AMARAL, A. L. Tecnologias da educação: ensinando e aprendendo com as TIC - guia do cursista. Brasília: Ministério da Educação, Secretaria de Educação à Distância, 2008.

PRENSKY, M. The emerging online life of the digital native: what they do differently because of techonology and how to they do it. 2004. Disponível em:

<http://www.marcprensky.com/>. Acesso em: 11 maio 2014.

PRENSKY, M. Digital natives digital immigrants. In: University Press, v. 9, n. 5, out. 2001. Disponível em: . On the horizon. NCB, 〈http://www.marcprensky.com/writing >. Acesso em: 13 mar. 2016.

SANTANA FILHO, S. F. O papel da biblioteca escolar na formação do leitor. In: CONGRESSO DE LEITURA DO BRASIL, 15., 2005, Campinas, SP. Anais eletrônicos... Campinas: UNICAMP, 2005. Disponível em: $\lfloor$ http://alb.com.br/arquivomorto/edicoes_anteriores/anais15/>. Acesso em: 05 maio 2015.

SANTOS, G. C.; AMARAL, S. F. Rede de conhecimento digital (BED Net): metodologia para a construção da rede de bibliotecas escolares digitais. Revista Brasileira de

Biblioteconomia e Documentação, São Paulo, v. 2, n. 1, p. 57-82, jan./jun. 2006. Disponível em: 〈http://www.febab.org.br/rbbd/ojs-2.1.1/index.php/rbbd/article/ view/6/22〉. Acesso em: 22 jul. 2015.

SELLTIZ, C. et al. Métodos de pesquisa nas relações sociais. 2. ed. São Paulo: EPU, 1987.

SILVA, E. T. Elementos da pedagogia da leitura. São Paulo: Martins Fontes, 1993.

VALENTE, J. A. Por que o computador na educação? In: SALGADO, M. U. C.; AMARAL, A. L. Tecnologias da educação: ensinando e aprendendo com as TIC: guia do cursista. Brasília: Ministério da Educação, Secretaria de Educação à distância, 2008. 